\begin{tabular}{c} 
Volume and Issues Obtainable at Center for Sustainability Research and Consultancy \\
Journal of Accounting and Finance in Emerging Economies \\
ISSN: 2519-0318ISSN (E) 2518-8488 \\
Volume 2: Issue 2 December 2016 \\
CSRᄃ \\
Journal homepage: www.publishing.globalcsrc.org/jafee \\
\hline
\end{tabular}

\title{
Financial Performance Indicators in Lebanese Hospitals: A Sustainable Improvement Strategy
}

\author{
${ }^{1}$ Hassan Alaaraj, ${ }^{2}$ Malak Aoun
}

${ }^{1}$ Lecturer, School of Economics, Finance and Banking, University Utara Malaysia, hkalaaraj@uum.edu.my

${ }^{2}$ School of Technology Management and Logistics, University Utara Malaysia,mallakaoun@hotmail.com

\begin{tabular}{|c|c|}
\hline ARTICLEDETAILS & ABSTRACT \\
\hline History & Although the quality of healthcare services has been measured extensively \\
\hline Revised format: Nov 2016 & using different approaches however; the financial approach is considered \\
\hline AvailableOnline: Dec 2016 & $\begin{array}{l}\text { one of the most tangible indicators to evaluate the effectiveness of the } \\
\text { implied quality improvement strategies at the Lebanese hospitals. It is }\end{array}$ \\
\hline Keywords & essential to measure quality of performance especially when hospitals are \\
\hline $\begin{array}{l}\text { Key performance indicators, } \\
\text { hospitals. }\end{array}$ & $\begin{array}{l}\text { competing for accreditation and sustainability. Therefore, this paper } \\
\text { highlights the significant key performance indicators applied by the }\end{array}$ \\
\hline $\begin{array}{l}\text { finance, } \\
\text { quality, }\end{array}$ & $\begin{array}{l}\text { Lebanese hospitals and mainly the financial performance indicators to } \\
\text { improve the healthcare financing in Lebanon. Such financial metrics are }\end{array}$ \\
\hline Lebanon & $\begin{array}{l}\text { found critical for hospitals to define and evaluate their performance } \\
\text { especially in terms of insurance and financial coverage. This paper }\end{array}$ \\
\hline $\begin{array}{l}\text { JEL Classification: } \\
P 17, P 19, P 36\end{array}$ & $\begin{array}{l}\text { demonstrates conceptually the current strategies for improving the } \\
\text { healthcare financing system in Lebanon yet, future studies are encouraged } \\
\text { to provide analytical elaborations for the financial status and relative } \\
\text { performance indicators of the healthcare system in Lebanon. }\end{array}$ \\
\hline
\end{tabular}

(C) 2016 The authors, under a Creative Commons Attribution-

NonCommercial 4.0

Corresponding author's email address: hkalaaraj@uum.edu.my

Recommended citation:Alaaraj, H., Aoun, M.(2016). Financial Performance Indicators in Lebanese Hospitals: A Sustainable Improvement Strategy. Journal of Accounting and Finance in Emerging Economies, 2(2) 69-75

\section{Introduction}

In concurrence with the trend of most hospitals towards the implementation of quality assessment strategies, the attention has been raised to improve patient care and hospital's performance while using the key performance indicators (KPIs). Such quality strategies have in its foundation the procedure of setting confident performance objectives to be measured by the suitable KPIs (Loan, 2012; El-Sayed, 2012).Hospitals have developed sets of KPIs to help it monitor the quality of healthcare services at different levels, such as employee's satisfaction, customer satisfaction, cost reduction and financial benefits (Sabry, 2014). Hence, this research goes in deep literature to illustrate the significance of using KPIs and especially at the financial level in the Lebanese hospitals where the implemented quality strategies reflect the hospital's determination to upgrade healthcare services and enhance the overall performance as well.

\section{Literature Review}


The development and implementation of KPIs in healthcare organizations and hospitals in particular, have been the main concern of most quality managers; as such indicators would improve the accountability and present data to evaluate the hospital's overall performance (El Sayed, 2012). In accordance withParmenter (2007), KPIs correspond to "a set of measures focusing on those aspects of organizational performance that are the most critical for the current and future success of the organization". Also, KPIs are defined as "measurement tools that should be specific, measurable, action oriented, relevant and timely" (Dunford et al, 2002). As for hospitals, Rodak, (2013) defined KPIs as metrics used to measure the hospitals' performance in terms of inpatient flow such as patient satisfaction, average length of stay, inpatient raw mortality rate, average cost per discharge, readmission rate, bed turnover, occupancy rate and surgical service.Moreover, Jiju (2007) mentioned that KPIs compose a set of performance metrics that help organizations define and evaluate how successful they are in making progress toward long-term goals and objectives. From a statistical perception, KPIs reflect the level to which an expected result is attained or the extent to which the quality of the procedures can lead to that result. Therefore, KPIs help managers provide continuous quality improvement, identify areas of excellence, compare between the actual performance and the imposed standards, and monitor corrective action as well (Sabry, 2014). In review of literature, KPIs related to healthcare sector have been addressed in different manners and categories that are relevant to the hospital performance. El Sayed (2012) illustrated that KPIs applied to assess quality in patient care are classified as (1) structure, (2) process and (3) outcome indicators. Structure KPIs present the inputs in health care provision including human, physical, and financial resources while process KPIs refer to the activities between health care practitioners and patients with a main focus on quality of care. As for outcome KPIs, it refers to the impact of these activities on a patient's current and future health status (Kalinichenko et al., 2013).

As reported by Chakrabarty et al. (2007), some KPIs are categorized in terms of competence and customer satisfaction however; there is a main focus on the financial benefits as well. Majority of literature review show that culture change, education and training,top management commitmentand financial benefits are the most significant indicators for the successful relevance of improvement strategies in service sector. In addition, Bandyopadhyay and Coppens (2005) listed four indicators to define the level of performance of a hospital including service cost,service level, clinical excellence and customer satisfaction. Also, Sabry (2014) mentioned that majority of KPIs include efficiency, time todeliver, reduced variation, quality service, employee's satisfaction, customer satisfaction, cost reduction financial benefits, and financial bottom lines. Moreover, Loan et al. (2012) listed focus on patient, efficacy, clinical efficiency, accountability, receptivity, safety, and financial resources management as major dimensions of KPIs in hospitals.

In the Lebanese context, there is a great emphasis on developing and implementing KPIs as a part of the improvement strategy to assess the hospitals' performance and monitor the quality of healthcare services in the country. Basically, the most common list of KPIs for the healthcare system in Lebanon includes the following indicators: patient centeredness,clinical effectiveness, safety, staff orientation, efficiency,client satisfaction, client flow and load, responsive governance, clinical practices and provider satisfaction (Romanos, 2012). Moreover, the Lebanese Ministry of Public Health (MOPH) has launched the tentative self performance assessment for hospitals, where five key performance areas were identified: (1) improvement of the overall public health status, (2) improvement of the quality of health care delivery, (3) improvement of health care financing and coverage for health services, (4) provision of cost effective and safe drugs and rationalization of their consumption and prescription, (5) strengthening of the MOPH preventive programs (MOPH et al., 2007). The objective of this research is to highlight the KPIs used in Lebanese hospitals from a financial perspective. Thus, KPIs from the area of health care financing are discussed more in details. 


\section{Overview of the Healthcare Financing in Lebanon}

The Lebanese healthcare system is a pluralistic and fragmented system which is characterized by multiple sources of financing, financing agents and providers. Besides to health status and service delivery, health financing is considered as a main key indicator for the healthcare system as a whole. There are many challenges facing the Lebanese hospitals mainly the payments shortfalls for public purchases, rising demand because of the refugees, rapidly rising costs, regulatory burden such as accreditation, and worker shortages basically nurses (Hobballah, 2013).In addition, the operating costs necessary for the work of these hospitals are divided into four main categories mainly salaries (43\%), maintenance and public health facilities (11\%), water and electricity (11\%), and $35 \%$ for purchases (CDR, 2005). Within these categories, the percentages may differ based on the operation of each hospital where there are many drivers of health costs as illustrated in Figure 1.

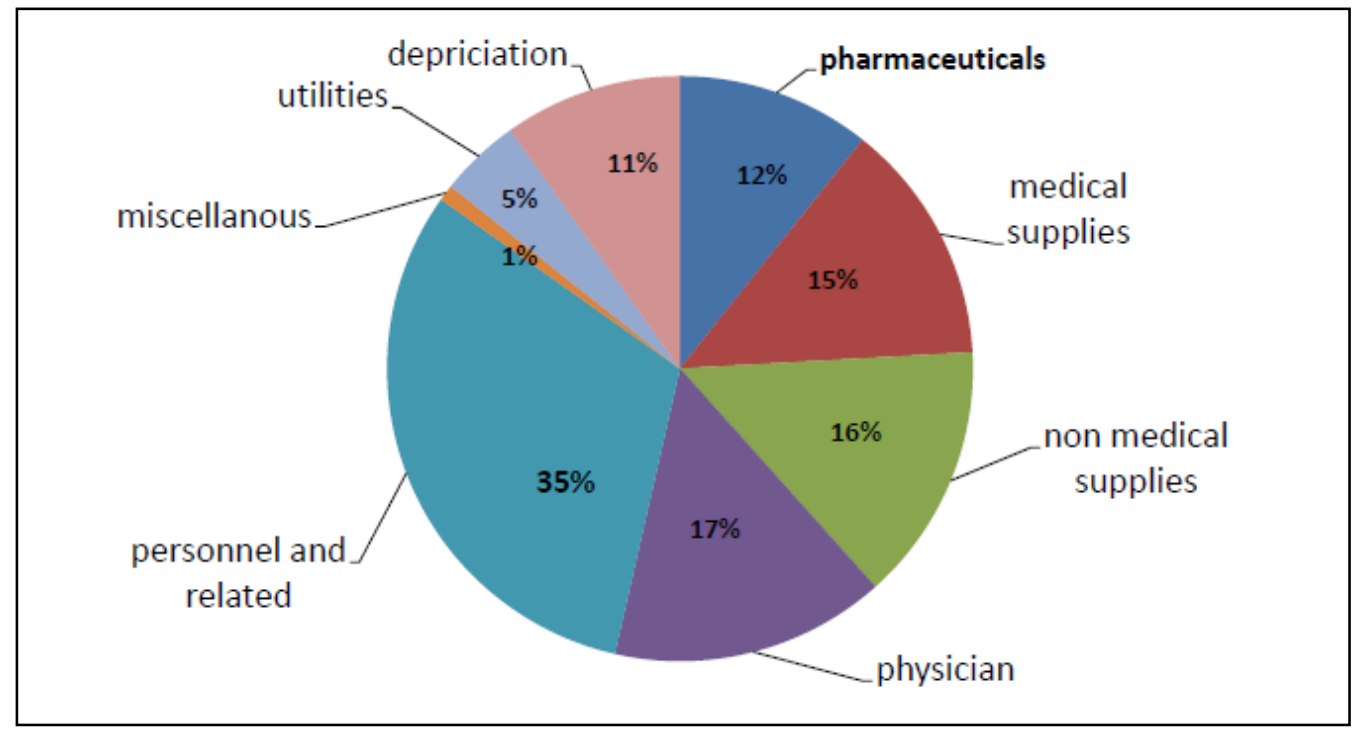

Figure1. Main Drivers of Health Costs (Hobballah, 2013)

On other hand, healthcare service delivery in Lebanon is insured and covered by different insurance schemes. Based on recent statistics, $38 \%$ of the Lebanese population is covered by the government funds including the Civil Servants' Cooperative (CSC), National Social Security Fund (NSSF), military schemes mainly internal security forces,army, public and state security. However, the private insurance companies cover only $8 \%$ of the population. The $54 \%$ outstandingpopulation are covered by the MOPH for healthcare services and high cost pharmaceutical (CRD, 2015).

\section{KPIs in Healthcare Finance}

The need for increased coordination in advanced quality care at minor costs has made it critical for hospitals to include quality control and development programs which rely on significant KPIs to continuously examine the hospitals' overall performance (El-Sayed, 2012). Mainly, hospitals focus on KPIs at the level of financial resources management to identify the available financial resources and settle on the means for an efficient resources allocation. Such KPIs include hospitalization services expenses,budget flow compared to approved budget; personnel expenses,emergency services expenses; and services expenses;average cost per day of hospitalizationandmedicine expenses (Loan et al., 2012).These dimensions of KPIs clarify how will hospitals and health systems lower costs within settings of care, provide more patient-centered, and utilize cost effectiveness research (Sabry, 2014). Moreover, Heuval et al. (2005) and Rivers (2010) state that hospitals have opportunity to reduce costs by eliminating wastes depending on three extents: reducing the time taken to complete a task, reducing errors in a process, and reducing the period that a patient stay at hospital to provide opportunities for 
more admissions. Also, Dileep et al. (2009) listed the KPIs for the health care process including cost per unit of service, throughput, cost/procedure, labor productivity and revenue enhancement.Particularly, AlEraij (2014) illustrated the major Financial Performance Indicators (FPIs) in hospitals through different dimensions. For instance, FPIs are used to measure the rate of bed turnover which reflects the length of stay by patients. In addition, FPIs measure the variation of cost per discharge, cost of outpatient visits, cost of salaries and overtime, cost of new operating and aging capital equipment, and inventory turnover including medications, general surgical and nursing supplies.

In the same context, the MOPH in Lebanon has identified two types of key performance indicators for the improvement of health care financing and coverage for health services (MOPH et al., 2007). First type includes effects and impact (EI) while the second type is more about activities, process and direct results (APR). Table 1 illustrates the main KPIs for each type.

Table 1. Public Health Sectoral Key Performance Indicators (MOPH et al., 2007)

\begin{tabular}{|l|l|}
\hline \multicolumn{1}{|c|}{\begin{tabular}{c}
\multicolumn{1}{|c|}{ Type (1) KPI } \\
Effects/ impact
\end{tabular}} & \multicolumn{1}{c|}{$\begin{array}{c}\text { Type (2) KPI } \\
\text { APR: Activities / Process / Direct } \\
\text { Results }\end{array}$} \\
\hline Health expenditures as \% of GDP & $\begin{array}{l}\text { Percentage of hospitalization budgetary } \\
\text { allocation in relation to the total public } \\
\text { health budget }\end{array}$ \\
\hline $\begin{array}{l}\text { Decrease in the percentage of out-of-pocket } \\
\text { share in health care expenditures. }\end{array}$ & $\begin{array}{l}\text { Percentage overshooting of expenditures } \\
\text { for hospitalization in relation to the } \\
\text { approved budget }\end{array}$ \\
\hline $\begin{array}{l}\text { Number of Insurance Providers implementing } \\
\text { the classification system of diagnosis related } \\
\text { groups (L-DRG) }\end{array}$ & $\begin{array}{l}\text { Percentage of public hospitals subsidies in } \\
\text { the total public health budget. }\end{array}$ \\
\hline $\begin{array}{l}\text { Percentage of total number of Insurance } \\
\text { Providers implementing the L-DRG }\end{array}$ & $\begin{array}{l}\text { Percentage of total planned hospitalization } \\
\text { subsidies controls effectively executed }\end{array}$ \\
\hline $\begin{array}{l}\text { Percentage of total number of hospitals whose } \\
\text { bills were controlled with a positive result }\end{array}$ & $\begin{array}{l}\text { Percentage of the total number of } \\
\text { hospitals of which the bills have been } \\
\text { controlled complying with the contract } \\
\text { requirements. }\end{array}$ \\
\hline $\begin{array}{l}\text { Percentage of population covered by a health } \\
\text { insurance }\end{array}$ & $\begin{array}{l}\text { Completion of the database of the clients / } \\
\text { beneficiaries of public funds }\end{array}$ \\
\hline $\begin{array}{l}\text { Percentage of population covered by a health } \\
\text { insurance, by type of insurance scheme }\end{array}$ & $\begin{array}{l}\text { Percentage of the total number of public } \\
\text { funds which are connected to the } \\
\text { insurance beneficiaries database system }\end{array}$ \\
\hline $\begin{array}{l}\text { Average degree of satisfaction of insured } \\
\text { population with insurance scheme, by type of } \\
\text { scheme }\end{array}$ & $\begin{array}{l}\text { Percentage of total number of centers } \\
\text { connected to the Database and providing } \\
\text { automated visa, by type of public funds }\end{array}$ \\
\hline $\begin{array}{l}\text { Average waiting time to get Ministry's approval } \\
\text { in hospitalization cases covered by MOPH }\end{array}$ & $\begin{array}{l}\text { Number of public funds that have } \\
\text { adopted the unified ratification scheme }\end{array}$ \\
\hline
\end{tabular}




\begin{tabular}{|c|c|}
\hline \multirow{2}{*}{$\begin{array}{l}\text { Composite indicator: Number of operational } \\
\text { ambulances and average covered population: } \\
\text { - Number of operational ambulance } \\
\text { - Percentage of population covered by } \\
\text { ambulance services } \\
\text { - Percentage of Public hospitals with } \\
\text { operational ambulances }\end{array}$} & $\begin{array}{l}\text { Number of public funds that link the } \\
\text { accreditation system to the pricing scheme }\end{array}$ \\
\hline & \\
\hline
\end{tabular}

\section{Common Challenges Facing the Use of KPIs}

As was discussed earlier, KPIs provide anapproach to noticewhether the strategic plan of a hospital is effective and it function as tools to drive the desired performance. However, it is not crucial to make KPIs appropriate to all health organizations in the same way. KPIs present quality feedback and focus the hospitals' management attention on what matters it the most. Although KPIs have been proposed recently along with different models for the evaluation of hospitals' performance, they still fail to deal with health system challenges as criticized by Loan et al. (2012). Such challenges may be short of uniformity in data collection and the lack of concurrence over the validity of KPIs used in the assessment procedures (El-Sayed 2012; Sobo et al. 2001).Moreover, Baroudi (2014) listed some frequent challenges that are featured when implementing KPIs. Basically, the objectives set by the hospital management are not clearly communicated and there is a lack of concurrence over these KPIs. In addition, the methods of computationmaybeuncertain or incomplete which in turn give insufficient amount of data. Furthermore, employees usually resist KPIs when profit and significance of measurements are not well understood. Also, the lack of knowledge on how to use KPIs effectively may also lead to such resistance.Besides, KPIs may be opposed if they are used as a means of punishment or the use of KPIs costs money, time and effort.

From the Lebanese perspectives, Haroun (2013) has pointed out that the hospitalization bill in Lebanon ranges between 600 and 650 million dollars a year, where the Lebanese government is responsible for 400 million dollars and the remaining 200 to 250 million dollars are accounted for private insurance companies and uninsured patients. Thus, the implemented KPIs for the improvement of health care financing and coverage for health services are essential to reduce such financial pressures, as to advance the correlation between public fundsandhealth care providers. Moreover, it is necessary to set the different sources of financing in equilibrium and rationalizeitin the course of conducting a National Health Accounts (NHA) study to monitor the flow of money in the health sector and implementing the classification system of diagnosis related groups (L-DRG) in hospital services (WHO, 2006).

\section{Conclusion}

Hospitals should constantlycomprise a flexible and innovative mindset when setting KPIs, as their eventualtarget is to drive the performance along with the corporate strategic plan of the hospital. Thus, health care organizations need to ensure that they use the right KPIs to maximize their outcomes into the future. The first step is to sort and select the most suitableassembly of KPIs. When thinking through the selection, it is essential to consider the KPIs' frequency, clarity of representation, ease of communication,strategic relevance and practicality. Especially at the financial level, it is significant to measure the performance using KPIs in order to provide quality feedback, support decision-making and encourage accountability which in turn serves as early warning signs to assign risks and responsibilities as well.

\section{References}


Al-Eraij, M. (2014).Financial Performance Indicators (FPIs).Presentation at the Ministry of Health \& HIMSS Middle East Conference and Exhibition. Jeddah: Saudi Arabia. http://www.himssme.org/moh14/docs/presentations/HIMSSME_MOH14_SpeakersPresentation_ MohamedAlEraij.pdf

Bandyopadhyay, J.K., \&Coppens, K .(2005). Six-Sigma approach to healthcare quality and productivity management.International Journal of Quality \& Productivity Management, 5(1), December 15.

Baroudi, R. (2014). Key performance indicators Winning tips and common challenges.Performance, $6(2)$.

CDR (2015).Public Health. Report (pp) 58-66. Social and Economic Sectors.Council for Development and Reconstruction. Lebanon: Beirut. http://www.cdr.gov.lb/arabic/progress_reports/pr102015/Apub.pdf

CDR (2005).Healthcare system in Lebanon.Report.Council for Development and Reconstruction. Lebanon: Beirut. http://www.cdr.gov.lb/Plan/Health/Arabic\%20Report.htm\#_Toc126053562

Chakrabarty, A., \& Kay, C.T. (2007).The current state of Six-Sigma application in services.Managing Service Quality, 17(2), pp.194-208.

Dileep, G., \& Rau, S. S. (2009). Applying Six-Sigma in health service: A study of critical success factors, critical to quality characteristics and key performance indicators in medium scale hospitals.International Journal on Information Sciences and Computing, 3(1).

El-Sayed, M. (2012).Measuring quality in emergency medical services: a review of clinical performance indicators.Emergency Medicine International, Vol.2012, ID 161630. Doi:10.1155/2012/161630

Haroun, S. (2013). Lebanese Republic Ministry of Information: national news agency. A Press Conference on 23 June 2013. Available at: http://www.nna-leb.gov.lb/ar/show-news/45997/

Heuval, J., Does, R., \&Bisgaard, S. (2005). Dutch hospital implements Six-Sigma. ASQ Six-Sigma Forum Magazine,4(2), pp.11-14.

Hobballah, A. (2013). Lebanese health care system: Challenge and solutions. MEDHEALTH Conference. Lebanon: Beirut.

Jiju, A. (2007). Six sigma and its role in financial services. The TQM Magazine,19(5).

Kalinichenko, O., Amado, C A. F., \& Santos, S P. (2013). Performance Assessment in Primary Healthcare: ASystematic Literature Review. Working Paper.

Loan, B., Nestian, A., \&Tiţă, S. (2012). Relevance of Key Performance Indicators (KPIs) in a Hospital Performance Management Model.Journal of Eastern Europe Research in Business \& Economics, Vol. 2012. ID 674169. DOI: 10.5171/2012.674169

MOPH; OMSAR; \&Central Inspection. (September, 2007). Report on Public Health Sectoral Key Performance Indicators. Ministry of Public Health, Beirut: Lebanon. Available at http://www.moph.gov.lb/Media/Pages/KPI.aspx

Rivers, J. R. (2010). Strategic issues forecast 2015. American Hospital Association (AHA) Committee on Research.

Rodak, R (2013). 16 Potential Key Performance Indicators for Hospitals.Becker's Hospital Review, May.

Romanos, A. (2012). Ministry of Public Health vision, planning and legislation.In the Lebanese Hospital in 2020 Conference, Med Health, Beirut.

Sabry, A. (2014).Factors critical to the success of Six-Sigma quality program and their influence on performance indicators in some of Lebanese hospitals.Arab Economics \& Business Journal, 9, 93-114. http://dx.doi.org/10.1016/j.aebj.2014.07.001

WHO (2006).Health Systems Profile-Lebanon.Regional Health Systems Observatory.World Health Organization.http://apps.who.int/medicinedocs/documents/s17301e/s17301e.pdf 